\title{
Healthcare Marketing On The Internet: A Review Of On-Going Concerns
}

\author{
S. Altan Erdem, (Email: erdem@cl.uh.edu), University of Houston, Clear Lake
}

\begin{abstract}
There is no doubt that the Internet has proven itself to be the most powerful vehicle for distributing information to millions of individuals. After all, it is interactive, user-controlled, and provides a means for communication detailed information across a vast spectrum of topics. When the topic is healthcare marketing, its popularity becomes even more eminent. There are over 25,000 Internet health sites and this number is climbing rapidly. On the other hand, there are many who are concerned about the healthcare marketing practices on the Internet. One of the basic premises of these concerns is based on the questionable accuracy of the information on the Internet and the crucial impact of this lack of accuracy when the information is about healthcare. This paper proposes various research propositions to understand the nature of these concerns and the potential future of healthcare marketing efforts on the Internet. It is hoped that future inquiries of these propositions and the ones alike provide a better understanding of the required components of the upcoming healthcare marketing strategies.
\end{abstract}

\section{INTRODUCTION}

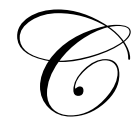

onsidering the fact that it took so long to recognize the role of marketing in the field of healthcare, one would have serious doubts when it comes to the use of the Internet in healthcare marketing. Yet, the growing use of the net in healthcare marketing appears to be the living testament to the popularity of the practice. We are now witnessing numerous practices in various forms such as telemedicine, Web-based treatments, interactive on-line medical consultations, e-hospitals, etc. It has been reported that there has been a 247 percent growth in the number of hospitals using the Internet for marketing over the last five years (Fell and Shepherd 2001).

While providers have been pursuing Internet-related strategies, patients have been incorporating the Internet into their routines too. Wilkins and Navarro (2001) stated that half of the Americans who are online were actually "health information seekers." Almost 100 million American adults regularly go online for information about healthcare (Wilson 2002). There is no doubt that the Internet is "working" for both sides in the field of healthcare. As Kerwin (2002) states, the Internet can be a key component of a healthcare organization's business and marketing strategy while improving the quality of patient care and satisfaction. Accordingly, one would expect that as the Internet gains more significance in different aspects of our lives, the world of healthcare bounds to increase its share of the Internet-use gradually.

\section{HEALTHCARE ON THE INTERNET}

Healthcare information on the Internet is both accessible and abundant. Using the Internet, patients can now access as much information as clinicians (Cline and Haynes 2001). It is no surprise that about six million Americans go online for medical advice on a typical day. According to the American Medical Association, more people go online for medical advice on any given day than actually visit health professionals. Interestingly, healthcare information is accessed more than sports, stocks, and shopping. One may wonder about the kind of information being sought. It has been reported that while women seek information about medical prescriptions and diagnostics, most men seek information about insurance and pharmaceutical companies (Wilkins and Navarro 2001). It has been reported that the heaviest users of the Internet for healthcare information are women in 40s seeking information to help them make healthcare decisions for their families. One interesting finding is that the majority of these users 
overall state that the Internet offers better information on certain topics such as new medication than what physicians or pharmacists have in their offices.

It is a common statement among these users that other major reason that they are going to the Internet for health information is their belief that today's doctor-patient relationship lacks an attention to detail and personal touch. In other words, they are online because they want more than what they get in a typical office consultation (Spielberg 1998).

As noted by some, the Internet is leveling the playing field. Tyson (2000, p. 4-5) states, "as the confidence consumers have in this new technology increases, their dependence on their doctor for information will decrease, along with the historical awe in which the omnipotent physician has always been held." This is a point one needs to consider in revising the marketing strategies of the healthcare providers.

\section{CONCERNS IN USING THE INTERNET FOR HEALTHCARE INFORMATION}

Several studies of online health content have concluded that web-based health information frequently contain inaccurate or misleading information and is often connected to efforts to sell products or services to consumers (Lissman and Boehnlein 2001). Anyone can add new sites with very little regulation or restriction. Quite often, these sites have unsubstantiated pages with information that is not truthful and/or designed to serve personal interests or agendas (Bernhardt et al. 2002). Unfortunately, according to the US Department of Health and Human Services, these kinds of websites making fraudulent claims have been on the increase.

In order to monitor the accuracy of the medical information on the Internet, in 1995 some of the Internet and telemedicine experts created the Health on the Net (HON) Foundation that is now used as one of the popular seals for healthcare websites. If a website subscribes to the voluntary code of standards established by HON, it can display the HON seal on its pages. Most of these standards are about making sure that the parties who give medical advice are medical professionals (or nonprofessionals who have to disclose their lack of expertise in those related areas). While this is a worthwhile effort, it has also been stated that HON standards are not comprehensive enough to eliminate somewhat questionable information on these sites. Unfortunately, the foundation does not serve as a watchdog due to its lack of formal power in the industry (Wolinsky 1998).

\section{Significance Of The Accurate Information}

In an online study of people who frequently visit health and medical web sites, $90 \%$ of respondents stated that they could manage their own health (Lack 1999). This continuous growth in the "self-care segment" suggests that there are times that some patients use these sites to diagnose their problems and self-treat without going to their doctors. When these patients 'diagnose' their symptoms, they may pursue some over-the-counter drugs that are not the 'best options' for their problems. Since they have the wrong information, they misdiagnose their symptoms, and pursue the options that they should not be pursuing. It is interesting to note that many physicians have been expressing their concerns about this problem by questioning the quality of the medical information on the Internet for a long time (Wolinsky 1998). These doctors are concerned about not only the not-so-safe self-treatments pursued by the patients but also the future of doctor-patient relationship when they have to explain those patients that their information is not always accurate. It appears that many patients who use the medical sites on the Internet do not realize the problems associated with the information they collect. One recent study states that only one-quarter of those seeking health information online check its source and timeliness (Conhaim 2003). Another study reports that $32 \%$ of patients who gather medication information from the Internet actually retain misleading information (Pucci 2003).

When a patient who acquired questionable medical information from the Internet meets with a physician who distrusts anything that any patient might download from the Internet, there is a potential for conflict between these two parties. Patients who use the Internet are increasingly taking responsibility for their health, even going so far as suggesting approaches to their physicians who are not that receptive at times (Conhaim 2003). These physicians are finding themselves uncomfortably upstaged by patients who arrive armed with information downloaded from the 
Internet (Coiera 1996) and the physicians do not like to be second-guessed by these patients (Kassirer 2000). When those patients are confronted by their physicians and realize that their physicians' suggestions contradict the information they obtained from the Internet, they get more confused and frustrated. So what starts as questionable medical information on the Internet ends up by being a serious problem that hurts the very foundation of the physician-patient relationship.

Since it is almost impossible to supervise the accuracy of the medical information on the Internet, it may be a good idea for physicians to develop their own websites and create some links between their sites and those third party sites that are credible based on the quality information they provide. After all, some patients will use the sources on the Internet regardless, and by this way, physicians can make sure that those patients use the "right" sources on the Internet. Considering the fact that medical doctors and medical organizations often are found to be the favored sources for health information (Bernhardt 2001), it makes perfect sense for physicians to develop their own websites. The following section elaborates more on these sites that physicians can develop.

\section{HEALTHCARE PROVIDER WEBSITES}

First of all, it is clear that physicians as well as health-providing institutions have a vested interest in encouraging patients to consult the Internet. After all, such behavior can cut down the time a physician needs to spend with a patient (Conhaim 2003). As in-office time is reduced per patient, the potential result is more cost efficient practice for the provider.

Providing patients with informative health information is a very valuable step for numerous providers. It has been reported that many patients do not fully comprehend all the information that they are presented with in the examination room. Offering an on-line medical bulletin board offers such patients an alternate outlet to use to improve their understanding of the issues without having to call their healthcare providers.

As suggested by Shinkman (2000), Internet-based practice management, catering to physician needs as well as customer needs, and coordinating patient appointments and referrals, can replace the unnecessary back-office management in the future. Having user-friendly websites allows them to address specific healthcare needs benefits of patients and practitioners alike. Patients are provided with valuable and comprehensive information at low cost. With complete information available to patients at the click of a mouse, one would expect fewer inbound calls made to doctors, leading to a reduction in overhead for the physician's office in the long run (Shepherd and Fell 1998).

Healthcare providers should build cross-functional teams composed of information technology (IT) professionals, medical specialists, healthcare administrators/ staff, patients, and, marketing specialists. These crossfunctional teams can bring different priorities and perspectives together in developing new ideas to be implemented on the Internet. While IT professionals are essential in developing proper online strategies, the human side of the topic in healthcare requires the other parties play rather active roles in determining the practical bases for the successful implementation (Flammini 2000). In case of websites, one has to make sure that they are designed in such ways that patients are able to use them to perform various functions such as having interactive discussions, completing forms, and scheduling appointments at the convenience of their home (Goedert 1999).

\section{Significance Of Personal Contact}

The fact that a physician has his/her website does not mean much unless that physician continues to have ongoing "personal contacts" with his/her patients. As stated above, the online alternative that a patient has would simply "cut down the time a physician needs to spend with a patient" but does not (and should not) eliminate it completely. A physician who maintains personal contacts with his/her patients and uses his/her website as an additional form of communication for further clarification develops stronger relations with those patients. Kemper's (2003) carryover effect suggests that when a patient trusts his/her physician, he/she tends to trust his/her physician's website, as well as a website that his/her physician recommends. 


\section{Encouraging Online Options}

By developing their websites and creating links to credible third-party websites, physicians can provide their patients with fine details on issues such as nutrition, diets, and disease prevention. Surgeons can display before-andafter pictures. While such communications could be made using traditional media, such as newspapers and/or magazines, these alternative outlets would be more expensive and primarily be effective in the short-run since they tend to be discarded once they are read. On the other hand, information posted to the Internet remains there until such time as the web sponsor decides to change the information. As new medial research becomes available, updates to the websites are made immediately. With complete information available to patients at the click of a mouse, one would expect fewer inbound calls made to doctors, leading to a reduction in overhead for the physician's office in the long run (Shepherd and Fell 1998).

Another way to recommend high-quality web sites to patients is to create patient education pamphlets listing Internet sources known to contain reliable and useful information. Such pamphlets should be given to the patients and the patients should be encouraged to review these sites prior to their appointments with their physicians. By this way, patients are provided with a source of quality information if they chose to educate themselves before meeting with their physicians.

\section{CONCLUSION}

Prior to 1980, the health consumer movement was not even on the radar screen (Magee 2002). Now, a short two decades later, national studies reveal a quite different reality. Patients are assuming a more active role in maintaining their health. Recognizing this new role, physicians are somewhat forced to recognize "partnership" type of relationships with their patients. In order these partnerships work efficiently, we need to make sure that patients are provided with the accurate information so that they can educate themselves properly. Since the role of the Internet in this education process is crucial, one has to make sure that the medical information on the Internet is monitored for its accuracy to the extent it is possible.

Accordingly, physicians should accept and incorporate Internet-related strategies into their practice. These online options should be developed as additional forms of communication with the patients. After all, the Internet can possibly provide the platform that may tie together the fragmented healthcare service providers, payers, and patients. The technology made possible by the Internet has the potential to establish communication channels between and among all of these parties. By using online channels, the efficiency in the marketplace is bound to improve and raise the level of satisfaction of its participants. The key is to examine the individual priorities among these participants carefully while developing the Internet-related strategies. It is hoped that the timely reviews of the various concerns like the ones listed in this paper result in continuous assessment of these strategies in the field of healthcare.

\section{REFERENCES}

1. Bernhardt, J. M. (2001), Tailoring Messages and Designs in a Web-based Skin Cancer Prevention Intervention, International Electronic Journal of Health Education, 4, 290-297.

2. Bernhardt, Jay M., Ruth Ann Weaver Lariscy, Roxanne L. Parrott, Kami J. Silk, and Elizabeth M. Felter (2002), Perceived Barriers to Internet-Based Communication on Human Genetics, Journal of Health Communication, 7, 325-340.

3. Cline, R. J. and K. M. Haynes (2001), Consumer Health Information Seeking on the Internet: The State of the Art, Health Education Res., 16, 671-692.

4. Coiera, E. (1996), The Internet's Challenge to Health Care Provision, British Medical Journal, 312, 3-4.

5. Conhaim, Wallys W. (2003), Is the Doctor Online? Link-Up@Home: Your Personal Guide to the Web, Information Today, (February), 29-31.

6. Fell, Daniel and C. David Shepherd (2001), Hospitals and the Web: A Maturing Relationship, Marketing Health Services, (Summer), 36-39.

7. Flammini, Steve (2000), Leveraging an Integrated HIS, Health Management Technology, 21 (8), 12-17. 
8. Goedert, Joseph (1999), Partners Healthcare System Uses the Internet to Integrate Its Delivery System and Foster Collaboration Among Physicians, Health Data Management, (December), 27-35.

9. Kassirer, J. (2000), Patients, Physicians, and the Internet, Health Affairs, 19 (6), 115-123.

10. Kemper, Donald W. (2003), Trust on the Health Internet, Managed Care Quarterly, 9 (1), 9-18.

11. Kerwin, K. E. (2002), The Role of Internet in Improving Healthcare Quality, Journal of Healthcare Management, 47 (4), 225-237.

12. Lack, J. (1999), The Web Doctor is In, American Demographics, (July).

13. Lissman, T. L. and J. K. Boehnlein (2001), A Critical Review of Internet Information About Depression, Psychiatric Services, 52(8), 1046-1050.

14. Magee, Mike, M. D. (2002), The Evolution of the Patient-Physician Relationship in the United States: Emancipation, Empowerment, and Engagement, Positive Profiles.com.

15. Pucci, E. (2003), Is the Internet Transforming the Physician-Consumer Relationship? Preliminary Data in a Neurological Setting, European Journal of Neurology, 10, 192.

16. Shepherd, C. D. and D. Fell (1998), Building Web Sites that Attract Visitors, Marketing Health Services, (Spring), 44-45.

17. Shinkman, Ron (2000), Back-Office, Online, Modern Healthcare, (January), p. 46.

18. Spielberg, A. (1998), On-call and Online, JAMA 280, 1353-1359.

19. Tyson, Ted R. (2000), The Internet: Tomorrow's Portal to Non-Traditional Health Care Services. The Journal of Ambulatory Care Management, 23(2), 1-7.

20. Wilkins, Stephen T. and Frederick H. Navarro (2001), Has the Web Really Empowered Healthcare Consumers? Marketing Health Services, (Fall), 5-10.

21. Wilson, Petra (2002), How to Find the Good and Avoid the Bad or Ugly: A Short Guide to Tools for Rating Quality of Health Information on the Internet, BMJ: British Medical Journal, 324 (7337), 598-600.

22. Wolinsky, Howard (1998), Physician's Role in Helping Patients Navigate the Web, ACP-ASIM Observer, (November). 


\section{NOTES}

